\title{
Postural Tachycardia Syndrome and Anxiety Disorder in Post-SARS-CoV-2- A Case Report
}

\author{
Sakthi Thava Priya C1, ${ }^{,}$, Dhakchinamoorthi Krishna Kumar ${ }^{1}$, Vijayan Abhilash', , Divya V, Sharnita P4, Sellappan Mohan² \\ 'Department of Pharmacy Practice, Karpagam College of Pharmacy, Coimbatore, Tamil Nadu, INDIA. \\ 2Department of Pharmaceutics, Karpagam College of Pharmacy, Coimbatore, Tamil Nadu, INDIA. \\ ${ }^{3}$ Department of Pharmacy Practice, PSG College of Pharmacy, Coimbatore, Tamil Nadu, INDIA. \\ ${ }^{4}$ Department of Psychiatry, Karpagam Faculty of Medical Sciences and Research, Coimbatore, Tamil Nadu, INDIA.
}

\begin{abstract}
Severe acute respiratory syndrome of coronavirus 2 (SARS-CoV-2) is a contagious deadly virus that had a significant impact on public health. It also causes a major impact on the lung complication with other comorbid disorders, such as cardiac and psychological conditions, which also leads to significant health and psychological burden to the patients. The restoration of the mental conditions among SARS-CoV-2 infected individuals becomes more essential. A 56-year-old female patient was admitted with chief complaints of dry cough and fever in the casualty care unit. She was diagnosed with positive SARS-CoV-2 infection and immediately admitted to covid care isolation wards. She was managed with antiviral drugs and other supportive care. Later, discharged with prednisone, oral anticoagulants, and vitamin supplements. Two weeks later she was presented with chief complaints of fatigue, palpitations, and dizziness diagnosed with Postural Orthostatic Tachycardia Syndrome (POTS) and anxiety disorder. Further, symptomatic management provided with a selective beta-blocker, anti-
\end{abstract}

arrhythmic drugs, and anxiolytic drugs. The present case report provides a basic insight into complications of POTS and anxiety disorder associated with post-SARS-CoV-2 infection. The appropriate therapeutic treatment and providing better counselling may improve daily activity and quality of life in patients reported with POTS symptoms.

Key words: Post SARS-CoV-2 infection, POTS, Anxiety disorder, Psychiatric distress, Cardiac complication, Supportive care.

Correspondence

Dr. C Sakthi Thava Priya,

Department of Pharmacy Practice, Karpagam College of Pharmacy, Coimbatore-32, Tamil Nadu, INDIA.

Email: thavapriya2812@gmail.com

DOI: 10.5530/jyp.2021.13.39

\section{INTRODUCTION}

In the past twenty years, most different geographical area was highly noted and reported with various widespread infectious outbreaks including Severe Acute Respiratory Syndrome (SARS) (2003), influenza virus with the H1N1 subtype (2009), Middle East Respiratory Syndrome (MERS) (2012), and Ebola virus (2014). ${ }^{1}$ The atypical cases with pneumonia was first reported on December 2019, Wuhan, China, which was identified and caused by the new RNA virion and it is grouped as Coronavirus. The new stain of severe acute respiratory syndrome coronavirus 2 (SARS COV-2 ) is considered a contagious deadly virus and had a significant impact on public health. ${ }^{2}$ In India the first SARS-CoV-2 case was reported on 30 January 2020 in Kerala. ${ }^{3}$ SARS-CoV-2 is a new strain, it is familiar to cause many diseases ranging from cold to severe respiratory illnesses including SARS and Middle East Respiratory Syndrome (MERS). ${ }^{1}$ The most common symptoms of the SARS-CoV-2 infection include pyrexia, chills, dry cough, sore throat, myalgia, nausea and vomiting, and also diarrhea. ${ }^{4}$ The major difference among the different coronavirus with SARS-CoV-2 is the rapid nature of spread and the virus remains active for a long time in the source or medium of spread.

During and after SARS-CoV-2 exposure many complications were reported which includes psychiatric disorders like post-traumatic stress disorder (PTSD), major depressive disorders, anxiety disorder and obsessive-compulsive disorder (OCD) ${ }^{5-7}$ Apart from psychiatric diseases, SARS-COV-2 is also associated with many central nervous system abnormalities like stroke, encephalitis, encephalopathy, anorexia, headache, nausea, and delirium. ${ }^{6}$
There were many pathological mechanisms involved in the proinflammatory mediators and SARS-CoV-2 infection which leads to a major contribution in the underlying pathophysiology of cardiac and arrhythmic complications. Several studies have been explained and reported the SARS-CoV-2 associated cardiac and neurological complications. ${ }^{8}$ Hence, patients are at even higher risk of cardiac arrhythmias and conversely patients often report postural orthostatic tachycardia syndrome (POTS). ${ }^{9,10}$

\section{CASE REPORT}

\section{Initial Observation}

A 56-year-old female patient was admitted with chief complaints of dry cough, mild dyspnoea, fever (on and off), and itchy throat at the casualty unit of the emergency department. She was a known case of hypertension. She was shifted to the screening ward for SARS-CoV-2 and the throat and nose specimen swab was taken for real-time polymerase chain reaction serology testing and was confirmed with a positive SARS-COV-2 infection. Her lab investigations revealed that elevated lactate dehydrogenase (396U/L), C-reactive protein $(\mathrm{CRP}=19.9 \mathrm{mg} / \mathrm{dl})$, ferritin, and interleukin-6 levels. Her vital parameters manifested as an increase in temperature $\left(100.4^{\circ} \mathrm{F}\right)$ with normal oxygen saturation measured by a pulse oximeter. Intravenous methylprednisolone $40 \mathrm{mg}$ and paracetamol one gm were administered as STAT order and she was later shifted to the emergency covid ward.

High resolution computed tomography (HRTC) showed moderate bronchitis with atelectasis and small bulla formation in the left lower

This is an open access article distributed under the terms of the Creative Commons Attribution-NonCommercial-ShareAlike 4.0 License, which allows others to remix, tweak, and build upon the work non-commercially, as long as the author is credited and the new creations are licensed under the identical terms. 
lobe and the CO-RADS score yielded category 6. Intravenous remdesivir $200 \mathrm{mg}$ was started as loading dose during in-hospital stay and dose was maintained with 100mg for 5 days. Oxygen saturation dropped from $98 \%$ to $94 \%$ with mild exertion. Supplemental oxygen (2 litres) was given for 5-7 hr to maintain saturation. During the hospital stay, she has developed shortness of breath and fatigue which was managed conservatively. A detailed description of symptoms along with the treatment regimen was given in Table 1 . The patient improved symptomatically and discharged with newer oral anticoagulants.

\section{Post COVID Observation}

The patient's signs and symptoms were improved within few days after discharged from the covid care ward. Two weeks later, she was reported and developed fatigue, mild headache, dizziness with palpitations especially while getting up from the sitting position and began to experience these symptoms. She was again tested for SARS-CoV-2 serology assessment and a negative result was obtained. Her electrocardiography showed sinus tachycardia and possible left atrial enlargement with no ischemic changes (Figure 1). She also developed orthostatic light-headedness and presyncope on the next day of admission. There was no abnormality seen in the brain magnetic resonance imaging.

Further continued examination shows that her heart rate was $86 \mathrm{bpm}$ and blood pressure of $120 / 85 \mathrm{mmHg}$ in sitting position. Her heart rate was $106 \mathrm{bpm}$ and her blood pressure was 105/74 mmHg upon standing position. Due to her complaints of orthostatic condition, it shows increased heart rate, she was examined and underwent head-up tilttable (HUTT) testing showed POTS within ten minutes of upright tilt.

\section{Table 1: Description of symptoms and treatment given to manage} SARS CoV-2.

\begin{tabular}{|c|c|c|}
\hline Days & Symptoms & Management \\
\hline \multirow[t]{9}{*}{ DAY 1-6 } & \multirow{9}{*}{$\begin{array}{l}\text { Dry cough, mild } \\
\text { dyspnoea, fever (on } \\
\text { and off) and itchy } \\
\text { throat. }\end{array}$} & $\begin{array}{l}\text { Injection cefoperazone and salbactum } \\
3 \mathrm{~g} \text { b.d }\end{array}$ \\
\hline & & Injection Paracetamol lg b.d \\
\hline & & $\begin{array}{l}\text { Injection Remdesivir } 200 \mathrm{mg} \text { as a loading } \\
\text { dose followed by } 100 \mathrm{mg} \text { daily }\end{array}$ \\
\hline & & Injection Methylprednisolone 40mg-b.d \\
\hline & & Tablet Pantoprazole 40mg-o.d \\
\hline & & Tablet Amlodipine 2.5mg-o.d \\
\hline & & Syrup Chlorpheniramine $5 \mathrm{ml}$-tds \\
\hline & & Nebulizer Duolin every $12 \mathrm{hr}$ \\
\hline & & Tablet Vitamin C and zinc supplements \\
\hline DAY-7 & $\begin{array}{l}\text { D Dimer test was } \\
\text { found to be positive } \\
(0.62 \mathrm{mg} / \mathrm{L})\end{array}$ & $\begin{array}{l}\text { Loading dose of Enoxaparin } 0.4 \mathrm{cc} \\
\text { followed by Tablet Abixaban } 2.5 \mathrm{mg}-\mathrm{bd} \\
\text { was added to regimen }\end{array}$ \\
\hline \multirow{3}{*}{$\begin{array}{l}\text { DAY8- } \\
10\end{array}$} & \multirow{3}{*}{$\begin{array}{l}\text { Shortness of } \\
\text { breath with sleep } \\
\text { disturbance and } \\
\text { decreased oxygen } \\
\text { saturation about } 94 \% \\
\text { was noted }\end{array}$} & Nebulizer Duolin every $8 \mathrm{hr}$ \\
\hline & & Tablet Alprazolam 0.5mg -HS \\
\hline & & Supplemental oxygen 2 liters was added. \\
\hline \multirow[t]{5}{*}{ DAY 11} & \multirow{5}{*}{$\begin{array}{l}\text { Significant } \\
\text { improvement in the } \\
\text { health condition } \\
\text { with no fever } \\
\text { for }>3 \text { days and } \\
\text { improved respiratory } \\
\text { symptoms was } \\
\text { observed. }\end{array}$} & Dis-charge medications: \\
\hline & & $\begin{array}{l}\text { Prednisolone Pulse therapy for } 3 \text { weeks- } \\
\text { b.d }\end{array}$ \\
\hline & & Tablet Abixaban 2.5mg for 4 weeks-o.d \\
\hline & & Vitamin supplements for 2 weeks \\
\hline & & $\begin{array}{l}\text { Advised to undergo self-quarantine for } 2 \\
\text { weeks. }\end{array}$ \\
\hline
\end{tabular}

o.d-once a day, b.d-twice a day, tds-thrice a day, HS-at bed time

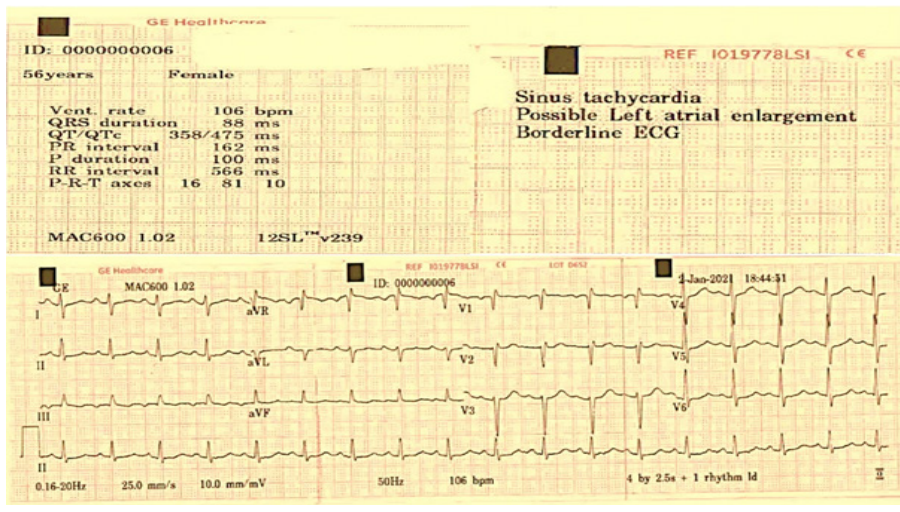

Figure 1: ECG taken after SARS-CoV-2 infection.

Her findings were very much consistent with the diagnosis of POTS and started with $\mathrm{T}$. Ivabradine $5 \mathrm{mg}$. This resulted in symptomatic improvement of her orthostatic symptoms and tachycardia.

After two days she was started and reported to develop mild gastrointestinal disturbances like indigestion, epigastric pain, nocturia along insomnia on the third day of admission which was managed with proton pump inhibitors, antacids, and a low dose of clonazepam $0.5 \mathrm{mg}$. She was agitated and felt inner restlessness for which baseline inflammatory markers like CRP, neutrophil/lymphocyte ratio (NLR), and monocyte/lymphocyte ratio (MLR) were checked and found to be normal. Using State-Trait Anxiety Inventory Form Y (STAI-Y). ${ }^{11}$ score was found to be 43 . She was diagnosed to have a moderate anxiety disorder, for which oral alprazolam $0.5 \mathrm{mg}$ and escitalopram $5 \mathrm{mg}$ were prescribed which improved her anxiety symptoms. The patient was discharged after 5 days from hospital wards, with observed mild improvement in her orthostatic symptoms and anxiety.

\section{DISCUSSION}

SARS-COV-2, besides the lungs also involves other body organs and causes stroke, encephalopathy, encephalitis, anorexia, headache, nausea, and delirium. ${ }^{6}$ In post-SARS-CoV-2 patients, changes in the functioning of more than one component of the autonomic nervous system (ANS) affect the health which leads to dysautonomia, thus focuses on the POTS. This condition is distinguished by a sustained increase in heart rate of $\geq 30$ beats/min within $10 \mathrm{~min}$ of standing or head-up tilt. The cardiologic symptoms include orthostatic intolerance, chest pain, palpitations, and exercise intolerance it is similar in our patient. ${ }^{12}$

Several possible pathophysiological mechanisms might be associated with post-SARS-CoV-2 POTS. One possible mechanism is a decrease in blood volume which is due to fever, excessive nocturnal sweating with a secondary increase in cardiac Sympathetic Norepinephrine System (SNS) outflow. Deconditioning with low stroke volume and high SNS or Sympathetic Adrenergic System (SAS) outflow with exercise intolerance and fatigue which is collectively called as Grinch heart have been noticed in POTS. Second, there is an increase in cardiac SNS outflow due to destruction and infection of extracardiac postganglionic SNS neurons by SARS-CoV-2 which leads to venous pooling during orthostasis. The third possible mechanism is increased central sympathetic outflow due to invasion of SARS-CoV-2 in the brainstem and alteration in functions of medullary centers. ${ }^{12}$ And the final one is autoimmunity in response to viral infection. If there is any disruption in balance- "Dyshomeostasis", POTS can occur hence in the presented case. ${ }^{7,12}$

The post-SARS-CoV-2 patients show a high prevalence of emergent psychiatric conditions including mood disorders, anxiety disorders, and insomnia. ${ }^{11,13}$ The cause of anxiety in SARS-CoV-2 patients can be one 
of the reasons for the high mortality rate, novel and unexplored, and its rapid transmission, also concerns about the future. ${ }^{14}$ Many studies have shown that SARS-CoV-2 affects mental health outcomes such as anxiety, depression, and post-traumatic stress symptoms. ${ }^{15,16}$ In this condition body's immune system weakens and there is an increase in the risk of contracting the virus when anxiety is above normal. ${ }^{17}$

Due to any social isolation, psychological impact and fatal illness, chances of infecting others also with the immune response to the virus can be the underlying consequences of psychiatric symptoms to SARS-CoV-2 infection. The immune response induces the production of many inflammatory mediators, cytokine and chemokine. ${ }^{18}$ Increased concentration of T-helper- 2 cell-secreted cytokines and their dysregulation were associated with psychiatric disorders. ${ }^{19}$

The possible relationship found between the immune system and psychopathological mechanism of psychiatric disorders includes dysfunction in the hypothalamic-pituitary-adrenal (HPA) axis, inflammation in the neuron, invasion of the peripheral immune cell into the CNS, impairment in neurotransmission, activation of microglia, disruption in blood-brain-barrier and induction of indoleamine 2,3-dioxygenase (IDO). ${ }^{17}$ Mild isometric exercises, repletion of fluid and salt, avoiding exacerbation, and compression garments would help in POTS. ${ }^{18}$ Pharmacological treatment includes Fludrocortisone, a fluid expander, were used in hypovolaemia persists patients.

Midodrine, used for the treatment of tachycardia and orthostatic hypotension. Further, hyperadrenergic symptoms were treated with clonidine and methyldopa. ${ }^{20}$ Several months after SARS-CoV-2 infection, many new symptoms and syndromes are emerging. Considering the great impact of SARS-CoV-2 infection on mental health, we would like to suggest early assessment of emergent anxiety conditions of SARS-CoV-2 infection survivors and treat them symptomatically.

\section{CONCLUSION}

The present case report provided insight information on anxiety disorder and postural orthostatic tachycardia syndrome (POTS) which was associated with post-SARS-CoV-2 infection in a female patient. The patient's quality of life was improved with appropriate treatment, counselling, and regular monitoring.

\section{CONFLICT OF INTEREST}

The authors declare no conflict of interest.

\section{ABBREVIATIONS}

SARS-CoV-2: Severe acute respiratory syndrome of coronavirus 2 SARS-CoV-2; POTS: Postural orthostatic tachycardia syndrome; MERS: Middle East Respiratory Syndrome; PTSD: Post-traumatic stress disorder; OCD: Obsessive-compulsive disorder; CRP: C-reactive protein; STAT: Latin team "immedietly"; HRTC: High resolution computed tomography; CO-RADS: Covid -19 reporting and data system; NLR: neutrophil/lymphocyte ratio; MLR: Monocyte/lymphocyte ratio; ANS: Autonomic nervous system; SNS: Sympathetic Norepinephrine System; HPA: Hypothalamic-pituitary-adrenal.

\section{REFERENCES}

1. Ashour HM, ElkhatibWF, Rahman MM, Elshabrawy HA. Insights into the Recent 2019 Novel Coronavirus (SARS-CoV-2) in Light of Past Human Coronavirus Outbreaks. Pathogens. 2020;9(3):186.

2. Bai Y, Yao L, WeiT, Tian F, Jin DY, Chen L, et al. Presumed Asymptomatic Carrier Transmission of COVID-19. JAMA. 2020;323(14):1406-7.

3. Pulla P. Covid-19: India's slow moving treatment guidelines are misleading and harming patients. BMJ. 2021;372:n278.

4. Chen N, Zhou M, Dong X, Qu J, Gong F, Han Y, et al. Epidemiological and clinical characteristics of 99 cases of 2019 novel coronavirus pneumonia in Wuhan China: A descriptive study. Lancet. 2020;395(10223):507-13.

5. Wu Y, Xu X, Chen Z, Duan J, Hashimoto K, Yang L, et al. Nervous system involvement after infection with COVID-19 and other coronaviruses. Brain Behav Immun. 2020;87:18-22.

6. Rogers JP, Chesney E, Oliver D, Pollak TA, McGuire P, Fusar-Poli P, et al. Psychiatric and neuropsychiatric presentations associated with severe coronavirus infections: A systematic review and meta-analysis with comparison to the COVID-19 pandemic. Lancet Psychiatry. 2020;7(7):611-27.

7. Cheng SK, Wong CW, Tsang J, Wong KC. Psychological distress and negative appraisals in survivors of severe acute respiratory syndrome (SARS). Psychol Med. 2004;34(7):1187-95.

8. Desai AD, Boursiquot BC, Melki L, Wan EY. Management of Arrhythmias Associated with COVID-19. Curr Cardiol Rep. 2021;2:2

9. Fedorowski A. Postural orthostatic tachycardia syndrome: Clinical presentation, aetiology and management. J Intern Med. 2019;285(4):352-66.

10. Benedetti F, Aggio V, Pratesi ML, Greco G, Furlan R. Neuroinflammation in bipolar depression. Front Psychiatry. 2020;11:71.

11. Vigneau F, Cormier S. The factor structure of the State-Trait Anxiety Inventory: An alternative view. Journal of Personality Assessment. 2008;90(3):280-5.

12. Goldstein DS. The extended autonomic system, dyshomeostasis, and COVID-19. Clin Auton Res. 2020;30(4):299-315.

13. Vindegaard N, Benros ME. COVID-19 pandemic and mental health consequences: Systematic review of the current evidence. Brain Behav Immun. 2020;89:531-42.

14. Banerjee D. The SARS-COV-2 outbreak: Crucial role the psychiatrists can play. Asian J Psychiatry. 2020;50:102014.

15. Cao W, Fang Z, Hou G, Han M, Xu X, Dong J, et al. The psychological impact of the SARS-COV-2 epidemic on college students in China. Psychiatry Res. 2020;287:112934.

16. Summaka M, Zein H, Naim I, Fneish S. Assessing the psychological impact of COVID-19 outbreak and its related factors on Lebanese individuals with physical disabilities. Disabil Health J. 2021;101073.

17. World Health Organization. Mental health and psychosocial considerations during the SARS-COV-2 outbreak, 18 March 2020. Geneva: World Health Organization; 2020. WHO/2019-nCoV/MentalHealth/2020.1.

18. Mazza GM. Anxiety and depression in SARS-COV-2 survivors: Role of inflammatory and clinical predictors. Brain, Behavior, and Immunity. 2020;89:594-600.

19. Ye $\mathrm{Q}$, Wang B, Mao J. The pathogenesis and treatment of the 'Cytokine Storm' in COVID-19. J Infect. 2020;80(6):607-13.

20. Freeman R, Abuzinadah AR, Gibbons C, Jones P, Miglis MG, Sinn DI, et al. Orthostatic hypotension: JACC State-of-the-Art Review. J Am Coll Cardiol. 2018;72(11):1294-309

Article History: Submission Date : 24-03-2021; Revised Date : 06-04-2021; Acceptance Date : 04-05-2021.

Cite this article: Priya CST, Kumar DK, Abhilash V, Divya V, Sharnita P, Mohan S. Postural Tachycardia Syndrome and Anxiety Disorder in Post-Sars-Cov-2- A Case Report. J Young Pharm. 2021;13(2):189-91. 